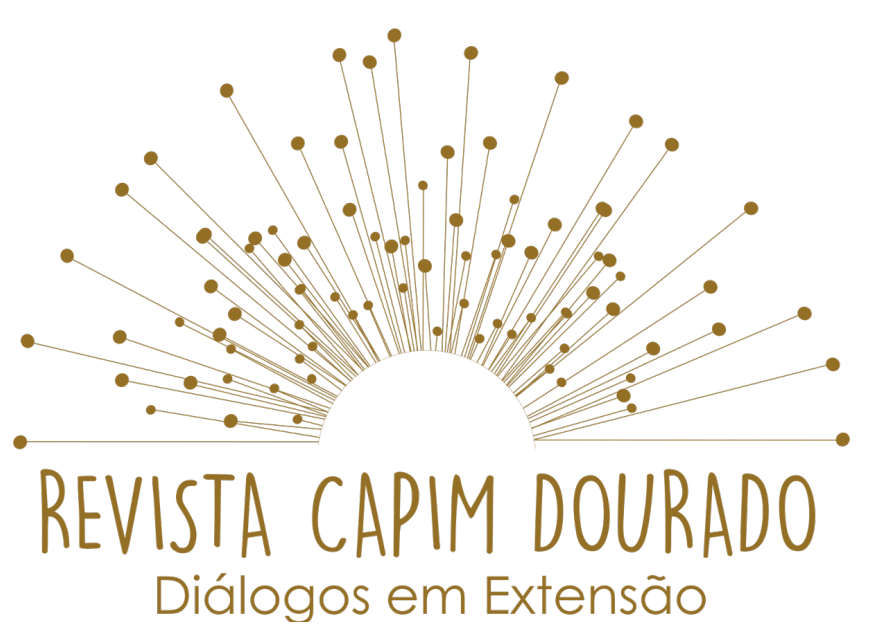

ISSN n² 2595-7341

Vol. 3, n. 2, Maio-Agosto, 2020

DOI: http://dx.doi.org/10.20873/uft.2595-7341.2020v3n2p81

\title{
A CONTRIBUIÇÃO DA UNIVERSIDADE NA PRÁTICA EXTENSIONISTA DE ASSESSORIA A ASSISTENTES SOCIAIS QUE ATUAM NA SAÚDE NO CONTEXTO DA PANDEMIA DA COVID19
}

THE CONTRIBUTION OF THE UNIVERSITY IN THE EXTENSIONIST PRACTICE OF ADVISING SOCIAL ASSISTANTS THAT WORK IN HEALTH IN THE CONTEXT OF COVID'S PANDEMIC19

LA CONTRIBUCIÓN DE LA UNIVERSIDAD EN LA PRÁCTICA EXTENSIONISTA DE ASISTENCIA A ASISTENTES SOCIALES QUE TRABAJAN EN SALUD EN EL CONTEXTO DE LA PANDEMIA DE COVID19

Raquel Cavalcante Soares ${ }^{1}$, Delaine Melo ${ }^{2}$, Ana Vieira ${ }^{3}$, André França ${ }^{4}$, Leila Benício ${ }^{5}$, Marcelle Nogueira ${ }^{6}$, Regineide Albuquerque ${ }^{7}$, Renata César ${ }^{8}$, Wanessa Pontes ${ }^{9}$, Jefferson Silva ${ }^{10}$, Julia Marques ${ }^{11}$, Emily Ferreira ${ }^{12}$, Julliana Araújo ${ }^{13}$, Karine Lessa ${ }^{14}$,Letícia Cristina de Assis ${ }^{15}$,

\footnotetext{
1 Mestra do curso de Licenciatura em ao em Serviço Social da Universidade Federal de Pernambuco, UFPE, Brasil., quelcsoares@gmail.com.

2 Docente do curso de Licenciatura em Serviço Social da Universidade Federal de Pernambuco, (UFPE), Brasil, delaine.melo@ufpe.br.

3 Universidade Federal de Pernambuco, (UFPE), anacvieira12@gmail.com.

4 Universidade Federal de Pernambuco, (UFPE), deofranca@hotmail.com.

${ }^{5}$ Universidade Federal de Pernambuco, (UFPE), leilabenicio@imip.org.br.

6 Médica Dermatologista pela USP, marcellenogueira@uol.com.br.

7 Universidade Federal de Pernambuco, (UFPE), regineide_albuquerque@hotmail.com.

8 Universidade Federal de Pernambuco, (UFPE), renata.cesar@upe.br.

${ }^{9}$ Universidade Federal de Pernambuco, (UFPE), wanessapontessso@hotmail.com.

${ }^{10}$ Universidade Federal de Pernambuco, (UFPE), jeffersonmello@outlook.com.br.

11 Universidade Federal de Pernambuco, (UFPE), juliameirelesmarques1@gmail.com.

12 Universidade Federal de Pernambuco, (UFPE), juliane.esf@gmail.com.

${ }^{13}$ Universidade Federal de Pernambuco, (UFPE), juliannaoma@gmail.com.

${ }^{14}$ Universidade Federal de Pernambuco, (UFPE), karinelessa00@gmail.com.

15 Doutora do curso de Licenciatura em Ciências da Universidade Federal de Lavras, leticiacristina97@hotmail.com.
} 


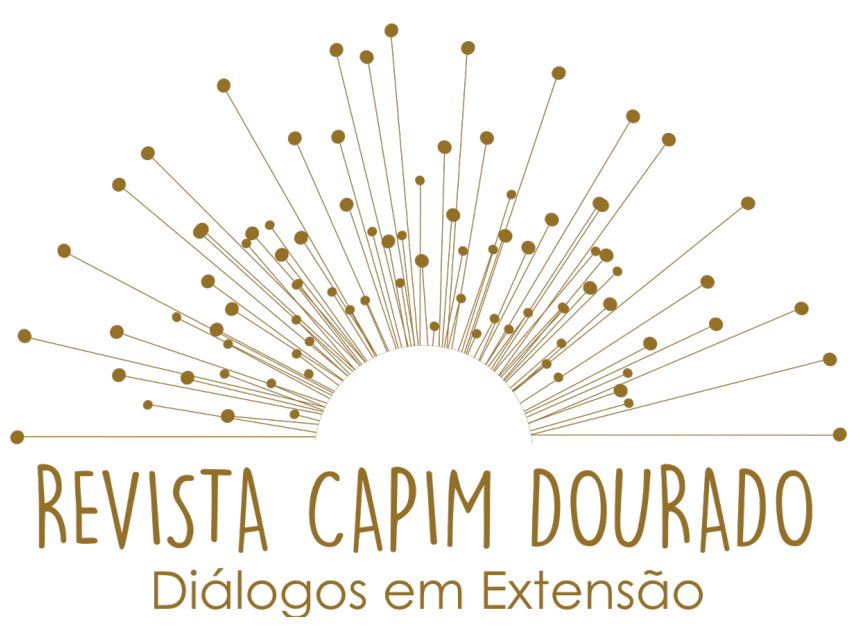

ISSN n² 2595-7341

Vol. 3, n. 2, Maio-Agosto, 2020

DOI: http://dx.doi.org/10.20873/uft.2595-7341.2020v3n2p81

\section{Mariana da Silva ${ }^{16}$, Mariana Larissa da Silva ${ }^{17}$, Thiago Henrique da Silva ${ }^{18}$}

\section{RESUMO}

O presente relato pretende discutir a contribuição das ações de extensão universitária para a assessoria de profissionais de saúde, particularmente assistentes sociais, no contexto da pandemia da Covid19. O projeto de extensão em questão encontra-se em andamento, mas já há resultados importantes que evidenciam as contribuiç̧̃es da extensão.

PALAVRAS-CHAVE: Extensão; Serviço Social na Saúde; Covid19.

\section{ABSTRACT}

The present report intends to discuss the contribution of university extension actions to the assistance of health professionals, particularly social workers, in the context of the Covid19 pandemic. The extension project in question is in progress, but there are already important results that demonstrate the contributions of extension.

KEYWORDS: Extension; Social Work in Health; Covid-19

\section{RESUMEN}

El presente informe pretende analizar la contribución de las acciones de extensión universitaria a la asistencia de los profesionales de la salud, en particular a los trabajadores sociales, en el contexto de la pandemia del Covid19. El proyecto de extensión en cuestión está en progreso, pero ya hay resultados importantes que demuestran las contribuciones de la misma.

\footnotetext{
${ }^{16}$ Universidade Federal de Pernambuco, (UFPE), mariana-Lrs@hotmail.com.

${ }^{17}$ Discente do curso de Licenciatura em Serviço Social da Universidade Federal de Pernambuco, UFPE, Brasil, mariana-Irs@hotmail.com.

18 Universidade Federal de Pernambuco, (UFPE), henrique 13thiago@hotmail.com.
} 


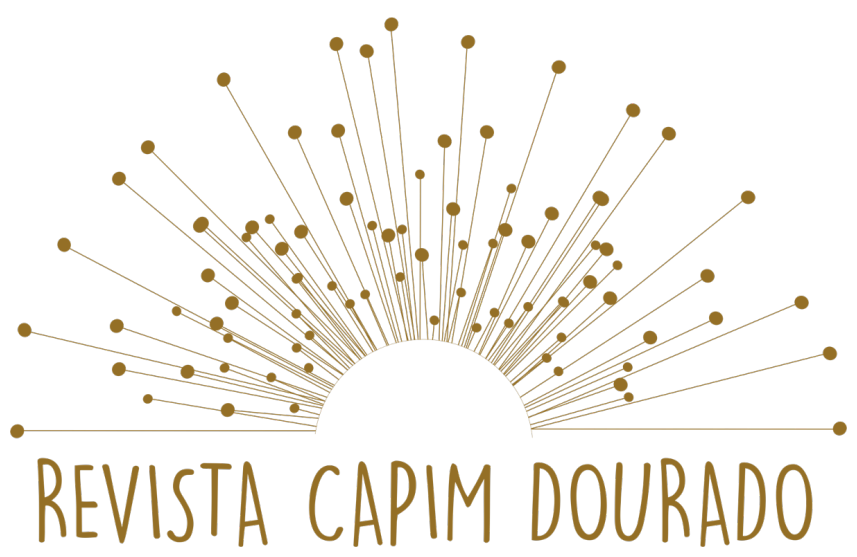

Diálogos em Extensão

ISSN n 2595-7341 Vol. 3, n. 2, Maio-Agosto, 2020

DOI: http://dx.doi.org/10.20873/uft.2595-7341.2020v3n2p81

PALABRAS-CLABE: Extensión; Trabajo social en salud; COVID-19.

Recebido em: 31.03.2020. Aceito em: 19.04.2020. Publicado em: 30.05.2020. 


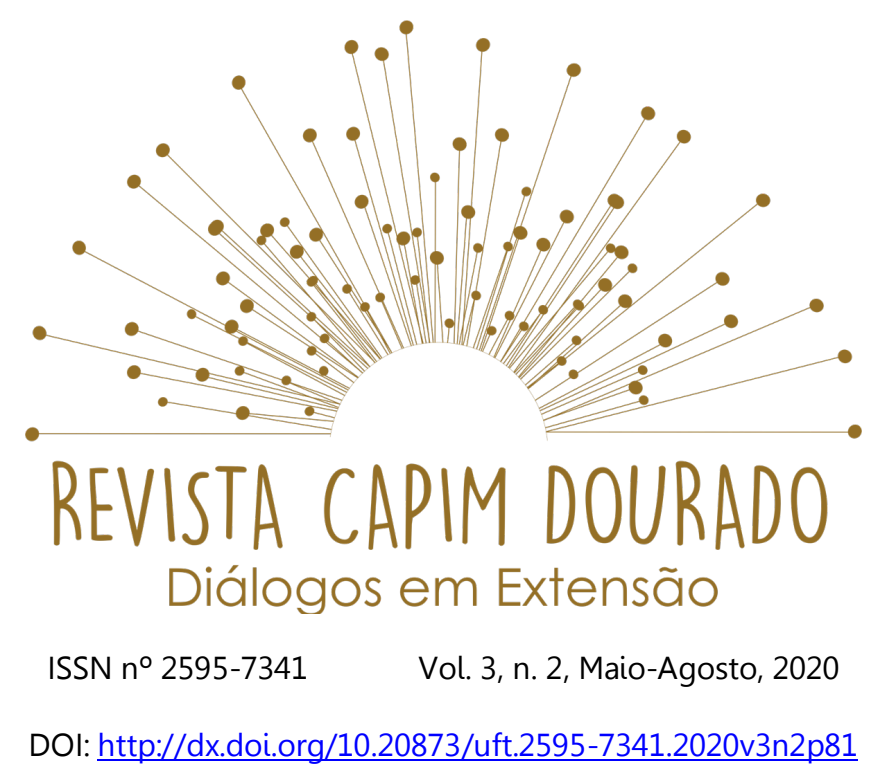

\section{O início de tudo: a pandemia da Covid19 e a questão sobre o que fazer}

Nosso projeto de extensão é resultado de um intenso processo de vivência do luto e transição para a luta, diante da pandemia da Covid19 e de sua complexidade na realidade brasileira - um dos países mais desiguais do mundo, com políticas sociais já bastante precarizadas e, particularmente, a política de saúde e o Sistema Único de Saúde (SUS), em situação de grave desmonte intensificado pela atual fase de contrarreforma e desfinanciamento.

Tais condições trazem grandes dificuldades e obstáculos ao enfrentamento à Covid19 no Brasil. Compondo equipes multiprofissionais de saúde que atuam nesse enfrentamento, estão inseridos/as assistentes sociais que atuam historicamente na área e que no seu cotidiano de trabalho lidam com as contradições do SUS e as expressões da questão social brasileira, que são objeto de sua intervenção profissional.

A política de saúde é um dos maiores espaços sociocupacionais de assistentes sociais no Brasil. Segundo dados do CNES (Cadastro Nacional de Estabelecimentos de Saúde) de fevereiro de 2020, há 31.875 vínculos de assistentes sociais que atuam no SUS (BRASIL.CNES, 2020). Importa ressaltar que - Serviço Social na política de saúde tem papel fundamental na articulação do sistema de saúde, na defesa de direitos dos/as usuários/as, na promoção da intersetorialidade entre as diversas políticas sociais, em atendimento às múltiplas demandas oriundas das expressões da questão social relacionadas ao processo 


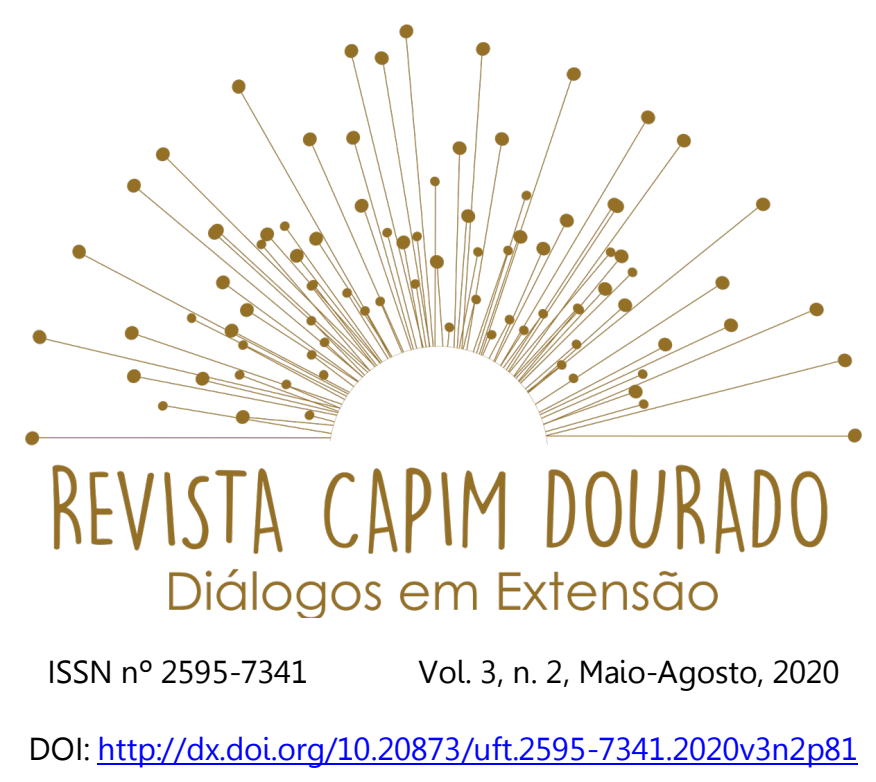

saúde-doença. Tais demandas tendem a se agravar no contexto da pandemia da Covid19.

Por se tratar de uma doença ocasionada por uma infecção viral e de fácil contágio, todas as rotinas e fluxos de atendimento nos serviços de saúde foram alterados para se adaptar a um contato interpessoal restrito e, com isso, diminuir a possibilidade de disseminação do vírus. Sendo assim, assistentes sociais foram desafiados/as a rever seu plano de atendimento ou mesmo construir protocolos específicos de atividades nos serviços de saúde no período de pandemia (MATOS, 2020).

Diante disso, questionávamos como contribuir com os/as assistentes sociais que estão na linha de frente na atuação no SUS neste contexto tão complexo. Como 3 (três) pesquisadoras/professoras do Departamento de Serviço Social de uma universidade de Pernambuco, aglutinamos um grupo de 8 (oito) estudantes de graduação que foram selecionados e tinham experiência de estágio na área da saúde. Além disso, convidamos 6 (seis) assistentes sociais da saúde que atuam em serviços de referência e têm histórico de comprometimento e defesa dos princípios ético-políticos do Serviço Social. Articulamos também uma parceria com o conselho regionalrofissional de Serviço Social do estado. Assim, construímos a proposição de realizar ações extensionistas de assessoria a equipes de assistentes sociais da saúde, criando espaços de socialização de conhecimento e debates sobre a prática profissional em meio à pandemia, os principais desafios e estratégias, no estado de Pernambuco, no período de maio a dezembro de 2020 . 


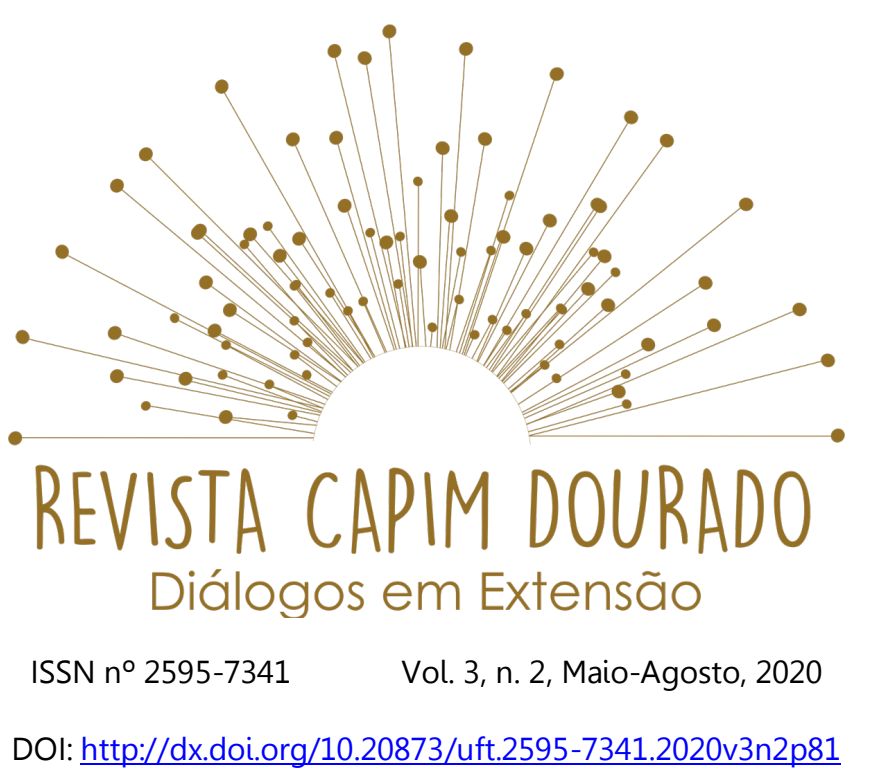

Elegemos como nosso objetivo geral, portanto, realizar ações de assessoria a equipes de assistentes sociais que atuam nos serviços de saúde no enfrentamento à pandemia da Covid19 em Pernambuco. Como objetivos específicos, destacamos: criar espaços virtuais de socialização das experiências e planos de enfrentamento à Covid19 por assistentes sociais da saúde em Pernambuco; Identificar e estimular o registro e planejamento das estratégias de enfrentamento à Covid19 das equipes de assistentes sociais que atuam na saúde em Pernambuco e, a partir disso, construir um banco de dados sobre essa intervenção no estado.

Este projeto vincula-se, assim, à linha de extensão de "saúde e proteção no trabalho", estando centrado na assessoria a trabalhadores assistentes sociais da saúde, com discussão sobre a prática social, tendo estes como público alvo direto. No entanto, também tem interfaces com as linhas de "direitos individuais e coletivos" - tendo em vista que atua promovendo a defesa dos direitos sociais e humanos junto aos profissionais que mais trabalham nessa perspectiva na política de saúde - e "saúde humana"- por estar vinculada a promoção à saúde numa concepção ampliada do processo saúde-doença e de sua determinação social.

Ao realizarmos este conjunto de ações extensionistas, ratificamos o lugar e a importância da universidade no enfrentamento à pandemia da Covid19 "democratizando o conhecimento acadêmico e aproximando-a da sociedade, oferecendo alternativas por meio de ações concretas com base científica e perspectivas de superação da situação atual." (BARBOSA, 2020: p 51) 


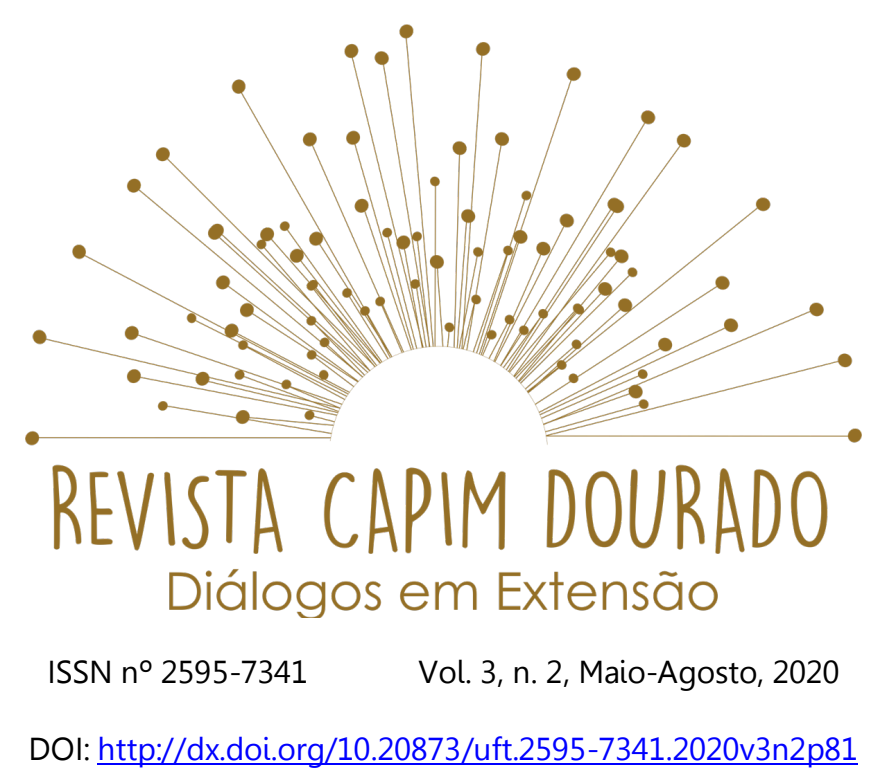

Este projeto, assim, integra aquilo que Ana Elizabete Mota (2020) defendeu como uma agenda temática instrumental e pedagógica que subsidie ações e práticas de profissionais no enfretamento à Covid19.

\section{Em meio ao percurso, a certeza que estamos no caminho certo}

A metodologia das ações está fundamentada nos princípios do projeto ético político profissional do Serviço Social e se desdobra nas seguintes atividades:

- levantamento/pesquisa bibliográfica e documental sobre o trabalho do assistente social na saúde no enfrentamento à Covid19 tanto para subsidiar a equipe do projeto de extensão quanto para ser socializado por email com as diversas equipes de Serviço Social dos serviços de saúde em Pernambuco. Elaboramos um cronograma de envio semanal de referências por e-mail para os assistentes sociais, e já estamos na $4^{a}$ semana de envio. Também, a partir do levantamento, iremos disponibilizar o acesso no GoogleDrive do link do nosso banco bibliográfico, a fim de que funcione como uma biblioteca virtual dedicada à temática do Serviço Social na Saúde no contexto da Covid19;

- Elaboramos um cronograma de lives realizadas com periodicidade quinzenal, com o objetivo de discutir os planos de intervenção e práticas profissionais dos assistentes sociais da saúde no enfrentamento à Covid19 em Pernambuco. Os debates levam em conta o contexto social e a conjuntura em que tais práticas são realizadas, porém, o principal foco de discussão é a prática 


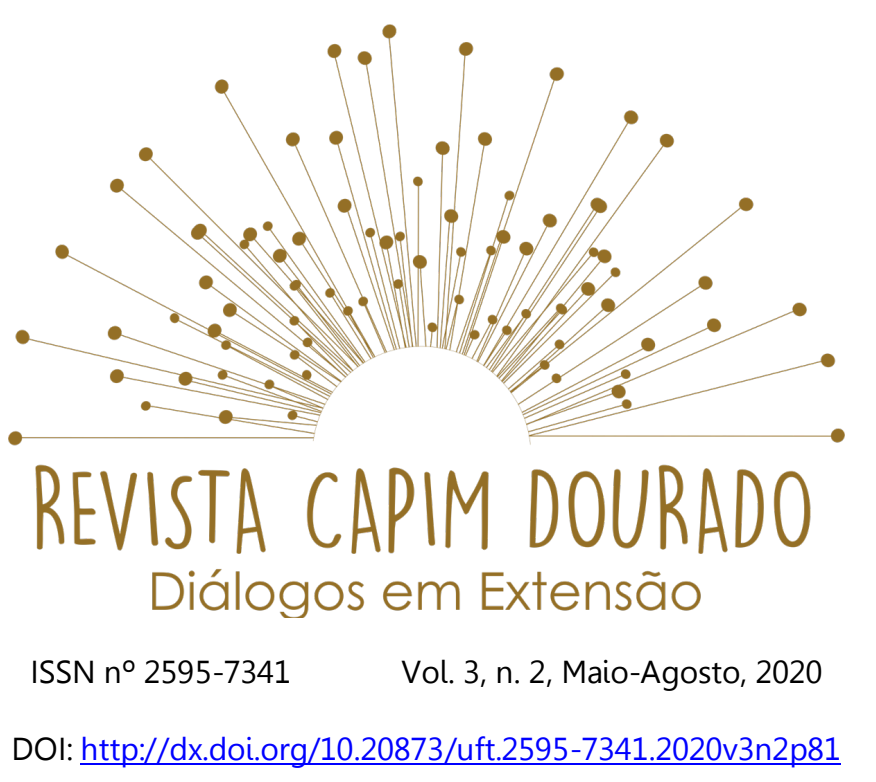

profissional a fim de socializar a experiência das equipes, contribuindo, com isso, com a elaboração de planos e fluxos de atendimentos coerentes com o projeto ético político profissional nos serviços de saúde. Realizamos neste período 3 lives discutindo e juntas elas já tiveram, no YouTube, mais de 3.400 visualizações. Também distribuímos formulário on line de avaliação das lives e todas têm alto índice de satisfação, com média de $84.37 \%$ de muito satisfeitos e $15.62 \%$ de satisfeitos. Pretendemos realizá-las até o final do projeto.

- Assim, a assessoria está sendo realizada via fomento e socialização das discussões nas lives, através da socialização das referências bibliográficas com as/os profissionais de Serviço Social e pretendemos também realizar reuniões virtuais com as equipes de assistentes sociais promovendo diálogos sobre seu cotidiano, sobre os planos de trabalho, desafios e estratégias, a fim de aperfeiçoar ainda mais as ações do projeto;

- realização de levantamento dos serviços de saúde que têm equipes de assistentes sociais atuando no enfrentamento à Covid19, bem como da existência ou não de planos/projetos específicos para intervenção no contexto da pandemia e suas principais características. A partir desse levantamento, estamos organizando um banco de dados que será, ao final do projeto, disponibilizado para o Conselho Regional de Serviço Social do estado, bem como arquivado pela coordenação deste projeto, a fim de servir de memória e subsidiar projetos de pesquisa.

Os resultados ainda a caminho e em desenvolvimento do projeto têm sido muito gratificantes - expressos nos diversos comentários dos/as assistentes sociais nas diversas ações realizadas, bem como pelos estudantes e profissionais 


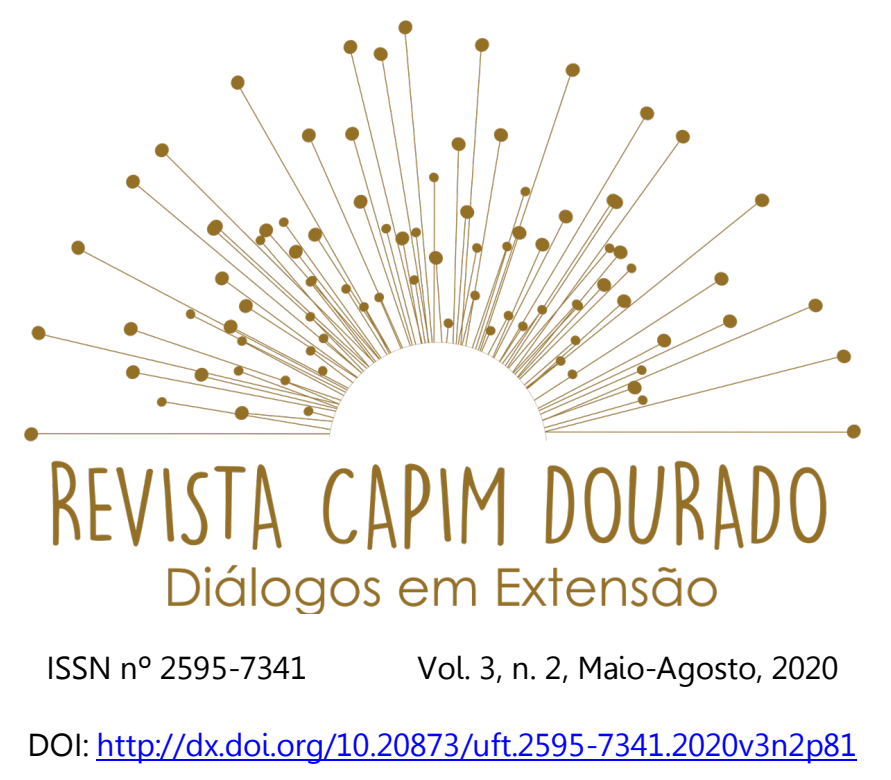

envolvidos na equipe de execução. Ademais, outros estados do país, a partir da divulgação do projeto nas redes sociais, estão multiplicando propostas semelhantes, como no Rio de Janeiro, em Alagoas e na Paraíba. É precisamente esta a razão de publicarmos nossos resultados, ainda que parciais: a necessidade de socializarmos esta experiência para que outras universidades também tenham acesso, inclusive cursos de outras áreas da saúde. Ações como estas expressam a importância e potencialidade da extensão universitária como uma prática social da universidade pública comprometida social, ética e politicamente com a vida.

\section{Referências}

BARBOSA, D. Saberes e práticas da extensão universitária na resposta ao enfrentamento da Covid19 no Brasil In Revista Práticas em Extensão. São Luís, v4, n1, 50-51, 2020.

BRASIL.CNES. Recursos Humanos. Fev/2020. Acessado em tabnet.datasus.gov.br/cgi/tabcgiexe?cnes/cnv/prid02br/def Disponível em 12/05/2020.

MATOS, M. A pandemia do coronavírus (Covid19) e o trabalho de assistentes sociais na saúde. Mimeo 2020. Disponível em: http://www.cress-es.org.br/wpcontent/uploads/2020/04/Artigo-A-pandemia-do-coronav\%C3\%ADrus-COVID-19-e-otrabalho-de-assistentes-sociais-na-sa\%C3\%BAde-2.pdf MOTA, Ana Elizabete. Desafios ao Serviço Social em tempos de pandemia. Live promovida pelo CRESSRN, no Instagran, dia 23/04/2020, às $20 \mathrm{~h}$. 